\title{
The Rubin Museum of Art: Re-Framing Religion for Aesthetic Spirituality
}

\author{
By: Gregory Grieve
}

Grieve, Gregory. "The Rubin Museum of Art: Re-framing Religion for Aesthetic Spirituality," Journal of Material Religion 3 (2006): 130-135.

Made available courtesy of Berg Publishers: http://www.bergpublishers.com/?tabid=517

***Note: Figures may be missing from this format of the document

Opened in New York on October 2, 2004, the Rubin Museum of Art (RMA)'s mission is "to establish, present, preserve and document a permanent collection that reflects the vitality, complexity and historical significance of Himalayan art." ${ }^{1}$ The seed for the RMA was planted in 1979 when the founders, Shelley and Donald Rubin, purchased their first thangka painting — an image of White Tara. The museum's location, at 150 West 17th Street, was identified in 1998, and the museum was founded in 1999, as a 501(c) (3) not-for-profit trust. The RMA's collection of approximately 1,200 objects includes paintings, sculptures, and textiles that reflect the major periods and schools of Himalayan art from the twelfth century onward and stretches from Afghanistan in the west to Burma in the east. Commenting on the scope of the Rubin collection, dealer Canton Rochell has described it as "a nearly encyclopedic collection [containing] every subject, every mahasiddha, lama, bodhisattva, and-deity in every form you could imagine" (Wallis 2005, 77).

While the collection consists of sculptures and textiles, the majority of its collection is made up of thangkas - water-based paintings on cloth canvas, which consist of a picture panel which is painted or embroidered, a textile frame, and one or more of the following: a silk cover, leather corners, wooden dowels at the top and bottom and metal or wooden decorative knobs on the bottom dowel. Thangkas — which simply means "something that can be rolled up" —originally were produced to be mounted, seen from al angles, and used in religious and health-related rituals (see Leoshko 1993: 16). In their original context, the images were important not for what they meant or who made them, but for their efficaciousness at aiding in a particular situation. Accordingly, rather than emphasizing reversibility, the artist's original intent, or even conservation, the approach of most painters would have been to repaint a damaged image or simply to make a new one (see Bruce-Gardner 1988, 26-31).

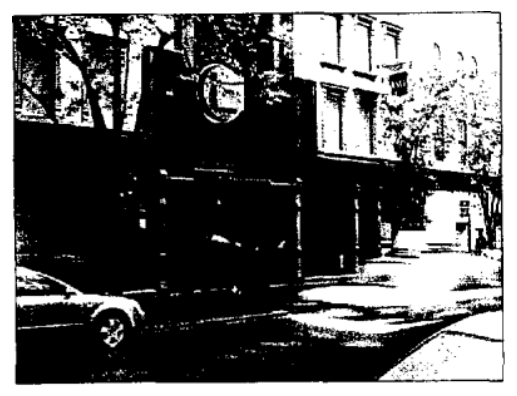

FIG 1

The RMA entrance. Photo: G Grieve 
One of the chief issues that the RMA has had to face is how to "translate" what are essentially Himalayan religious objects into the space of an American fine arts institution. The RMA, has by its own account, succeeded — at some cost—by transforming the images from ritual devices into aesthetic spiritual images. The clearest indicator of this aesthetic transformation is that the vast majority of the paintings have been literally "re-framed." Their original brocaded silk borders and dust curtains have been replaced with modern silver frames. Some of the reframing occurs simply because of conservation. The silk borders are the most vulnerable part of the paintings, and are quickly weakened by damp walls, the weight of the heavy bottom rod, and especially the repeated rolling and unrolling of the paintings for ritual display. Yet, as Jacques Derrida reminds us in The Truth in Painting, rather than mere ornament, the frame is the "decisive structure of what is at stake" (Derrida 1987, 61).

Two discourses are at play in the RMA's re-framing of the paintings. First, the thangkha paintings are now displayed as pieces of art to be hung on the museum's walls, and have been encapsulated in the discourse of fine art viewing. According to the opening curator, Rob Linrothe, the RMA did all it could to avoid creating a "faux Tibetan temple... We need to communicate that this is not a Buddhist Museum or a Tibetan Museum, it is an art museum" (Doran 2004: 34). Rather than being displayed as ethnographic curiosities particular to one culture, the paintings are shown as fine art pieces that reflect human creative genius. Museum co-founder Shelly Rubin states, "Certainly we would file people to appreciate this art not on the level of a curiosity but on the same level that they appreciate a Rembrandt or a Monet" (2004, 39).

If the RMA is displaying fine art, what differentiates it from, say, the display of Himalayan art at the Metropolitan Museum of Art? The answer is that the RMA seeks to underscore this fine art's spiritual dimension. The brochure that museum-goers receive along with their admission ticket re-frames thangkas in a "symbolic language [that] plays an important part in Himalayan art," one that "communicates directly to everyone."2 One FAQ from the RMA website claims that the paintings answer the "probing enduring questions of humankind. Himalayan art engages modern consciousness with uncanny precision." And in a volume produced by the RMA, the Buddhist monk Matthieu Ricard argues that the "[a]rt awakens in the mind a direct experience deeper than our ordinary sefves and the material world" (Linrothe and Watt 2004: XV). Museum co-founder Donald Rubin suggests that this engagement is possible because "[a]rt comes from the human unconscious... [It] speaks to anyone across cultures and across time" (Doran 2004, 38). At the heart of this interpretation is the notion that viewers of these works will experience an "emotional rush." In Mr. Rubin's words, viewing the paintings is "like when you fall in loveyou take a step back and feel the emotional energy coming through" (Doran 2004: 37). This emotional rush is seen as important, because as Caron Smith, the Deputy director, Chief Curator, RMA suggests: "Art is not a thing, it is a Verb. It is something that happens between an individual and an object" (Huberman n/d).

For at least some practitioners of Tibetan Buddhism, the RMA's re-framing of the thangkas does not trouble their notions of cultural authenticity. For instance, when asked what they thought of the metal frames, a group of Tibetan monks simply wanted to know where they could purchase similar ones. ${ }^{3}$ But because the paintings are re-framed as aesthetic objects, 


\section{PICTURE IS OMITTED FROM THIS FORMATTED DOCUMENT}

they necessarily are extricated from their social use in religious ritual. On the one hand, the thangkas de-socialized display continues a romanticization of the Himalayas region as a timeless Shangrila. On the other hand, it leads to the RMA's genuine bafflement when encountering pollitical protest to its exhibition, "Tibet: Treasures From the Roof of the World," a collaboration with the Peoples' Republic of China's Bureau of Cultural Relics.

Gregory Price Grieve

University of North Carolina, Greensboro Department of Religious Studies

Notes and References

1. The official portal for the RMA is http://www.rmanyc. org/ (accessed Aprif 11, 2005).

2. From a Rubin Museum of Art Pamphlet, Designed by Mifton Gfaser, Inc [procured January 2005)).

3. Personal communication with Lisa Schubert, Vice President of Special Projects RMA (April $5,2005)$.

Bruce-Gardner, Robert. 1988. Himalayan Scrofl Paintings: Conservation Parameters. The Conservator 12: 26-31.

Derrida, Jacques. 1987. The Truth in Painting. Trans. Geoff Bennington and Ian McLeod. Chicago, IL: University of Chicago Press, p. 61.

Doran, Valerie. 2004. Dispfaying Benevolence: The Rubin Museum of Art. Orientations 35: 34. Huberman, Martin. No date. Transformation: Building the Rubin Museum of Art. DVD. New York: VideoArt Productions.

Leoshko, Janice. 1993. The History of the Art History of Tibetan Art. Western Association for Art Conservation 15: 16.

Linrothe, Rob and Watt, Jeff. 2004. Demonic Divine: Himalayan Art and Beyond. Chicago, IL: Serindia Pubfications, p. XV.

Waflis, Stephen. 2003. Fierce Protectors. Art and Auction April: 77. 